\title{
Legal and organizational healthcare environment for the children with primary immune deficiency disease in Russia
}

\author{
Andrey Nechkin ${ }^{1, *}$, Ekaterina Zaitseva ${ }^{2}$, and Lyudmila Voronina $^{2}$ \\ ${ }^{1}$ Ural State Law University, Komsomolskaya str., 21, Yekaterinburg, Russia \\ ${ }^{2}$ Ural Federal University, Mira str., 19, Yekaterinburg, Russia
}

\begin{abstract}
The aim of the research, the results of which are presented in the given article, comprises studying the state of legal and organizational healthcare environment provided to the Russian children with diseases caused by primary immune deficiency, as well as identifying the prospects for creating such environment. The relevance of the theme under study is due to the fact that the number of patients with diseases caused by primary immune deficiency is increasing in many countries, including the Russian Federation. This group includes more than 450 different diseases caused by defects in cells and proteins that are the components of the immune system. A significant number of Russian children suffer from diseases caused by severe combined immune deficiency: this is one of the most dangerous forms of primary immune deficiency disease. Hereditary conditions begin functioning even before the birth of a child, they are difficult to diagnose, often have fatal consequences, such as director disability and death. Their treatment requires special resources, such as high-tech medical care, emergency treatment, the use of special medical technologies, personnel and financial support. The authors of the article prove that difficulties and problems can be minimized in case of the implementation of the specific legislative and organizational actions.
\end{abstract}

\section{Introduction}

The healthcare of different countries including the Russian Federation presupposes that there has been the adopted classification of clinical diseases. One of these constantly increasing clinical groups is the group of patients with diseases caused by congenital immune errors also called primary immune deficiency diseases. It includes more than 450 different diseases caused by defects in components of the immune system, such as cells and proteins, or a genetic "malfunction".

Although the primary immune deficiency is a rare disease, but its individual types can be more frequently observed than other known hereditary conditions can. In case of the absence of treatment or poor-quality treatment, the patients can suffer from these diseases during a whole lifetime. These diseases, as a rule, begin at birth, can be characterized as severe, often cause fatal consequences.

One of the most dangerous forms of primary immune deficiency disease is severe combined immune deficiency (hereinafter referred to as SCID) [1]. Unfortunately, a significant number of Russian children suffer from the diseases caused by severe combined immune insufficiency.

Therefore, the task of practitioners and researchers is to determine the treatment strategy, including the use of various technologies (such as medical and management ones). Both Russian and foreign researchers note that children who suffer from severe diseases cause a serious problem not only for their families and doctors in particular, but also for the society on the whole. They suffer from inveterate and often very serious diseases all their lives long, and their treatment requires huge costs for the healthcare system due to the need for constant assistance [2]. They require long hospital stays, intensive care, and the use of special technologies [3].

Children with a complex medical status, including those with SCID, are characterized not only by special medical needs, but also by special social needs [4]. Accordingly, the conducting of the research requires classifying the problems typical of children patients with complex diseases, including SCID.

The authors of the article share the opinion of those who propose to classify the relevant studies according to three results: clinical, economic and humanistic [5]. But, due to the authors of the article, it is advisable to supplement the classification within the study of problems in the socialization of patients through the provision of services by educational institutions (such as the institutions of preschool, school and additional education) and cultural institutions [6].

And it is also advisable to highlight the problems of legal regulation that arise within the provision of medical services for children patients with diseases caused by SCID. 


\section{Methodology}

Children with SCID, from the moment of diagnosis, constantly need to receive medical services. As defined in Federal Law No. 323-FZ dd. 21.11.2011 "On fundamental healthcare principles in the Russian Federation", "Medical Service is medical treatment or a complex of medical treatments aimed at the prevention, diagnosis and treatment of diseases, medical rehabilitation having an independent completed value". This definition allows us to consider medical treatment as a set of measures aimed at maintaining and (or) restoring of health and including the provision of medical services [7].

At the same time, such types of medical intervention as preventive, diagnostic, therapeutic, rehabilitation activities, medical examinations and (or) medical manipulations are significant for SCID children [7]. The medical intervention proxy is to be agreed with the child's representative, i.e. the parent or the guardian.

No doubt that, in general, Federal Law No. 323-FZ protects the right of a child patient to get various types of medical services. But the study of children's medical records, as well as the results of Russian [1] and foreign [8] research, allows us to conclude that the main problem in the treatment of children with diseases caused by SCID is the untimely conducting of neonatal screening and the conducting of other genetic diagnosis activities necessary to clarify the type of disease and treatment methods.

There arises a logical question concerning the causes able to explain the time-lag of making the genetic diagnoses or its non-implementation? The research team of immunologists led by I.A. Tuzankina explains this paradox as follows: "Despite the significant progress in the diagnosis and treatment of primary immune deficiency disease observed recently in many countries of the world, most of the Russian patients with SCID die undiagnosed. The main problem of primary immune deficiency disease in the Russian Federation as well as for all the rare diseases is under-diagnosis due to both the lack of alertness of primary care specialists, especially pediatricians, and the low availability of modern methods of molecular genetic analysis in everyday clinical practice [9].

Such factor as the low availability of modern methods of molecular genetic analysis, according to the author's opinion, is due to the following factors: Federal Law No. 323-FZ does not guarantee the sending of child patients to genetic diagnosis specialists. Doctors may not send a newborn child for neonatal screening (which is one of the types of genetic diagnosis). The attending physician should prescribe a certification for genetic diagnosis to a sick child, even if there is a suspicion of primary immune deficiency. The cost of conducting genetic research is high. As a rule, it is not included in the budgets of medical institutions and, accordingly, in the budgets of the subjects of the Russian Federation. The answer to many questions is simple: the analyzed federal law does not contain a legal norm on obligate genetic diagnosis.
The negative consequences are complex. The number of them includes the following. 1) The quality of medical services is declining. 2) The child-patients are not provided with the necessary medical services, namely, genetic diagnostics. 3) The treatment prescribed by the doctor is usually improper. 4) As a result, the child's number of diseases caused by undetected primary immune deficiency or SCID increases. 5) Then disability comes, and in some cases, even the death of a child.

The following conclusion can be formulated: the rights of a child patient are violated as a result of not providing the necessary medical services or malpractice and improper provision of medical care. S.M. Grishin notes that in Russia in 2015, more than 700 people died due to malpracticing and improper provision of medical care, including 317 children (according to the materials of the speech of the Chairman of the Investigative Committee of Russia Alexander Bastrykin made at the meeting of the board devoted to the organization of the investigation of crimes related to poor-quality of medical care) [10]. In the Sverdlovsk region, over the past 5 years, 150 children suffering from the diseases caused by SCID have died (according to the results of studying the registers of diseases caused by SCID).

Should the doctors, even in the absence of the federal law, be guided by the current normative acts regulating the provision of medical services? But even in this situation, the following problem arises. The normative acts contain the concept of "medical care" (see Federal Law No. 323), but it is very vague, which creates difficulties for both doctors and patients in determining the types of medical services and, most importantly, in determining the results of receiving such services. Thus, the text of the National Standard of the Russian Federation specifies that a service can be considered the result of direct interaction between the service provider and the service consumer, as well as the result of the service provider's own activities to meet the needs of the service consumer [11].

A medical service is classified as a socio-cultural (non-material) service. The patient is considered to be a consumer, customer, and user of services. The application of GOST (The National Standard of the Russian Federation), version 1509000 allows us to consider the provision of services as an action (or a set of actions), as a process or a set of individual stages. Its implementation requires resources, compliance with the technological process of execution, control and evaluation of results, including the service process. We note that the process approach used for organizing services allows you to develop technologies and successfully apply them. This statement is fully acceptable for medical services, including the technology of genetic diagnostics carried out to detect a hereditary disease.

The Russian Federation also has the experience of positive practice of expert forensic activities aimed at the development and application of molecular genetic research technologies. Forensic medical examination of personality identification and establishing kindred is considered as a technology. Accordingly, there is a local act and norms which allow to conduct such actions and 
carry out the corresponding procedures. There has been established kinship within the forensic medical examination of identity that is considered as technology. There has been established an object of forensic molecular genetic expert researches. The requirements for the premises where molecular genetic studies are carried out are described, as well as the precautions that ensure the biosafety of the working process.

Specific methods are named, for example, enzymatic amplification of DNA molecules, the lists of necessary equipment, a technological scheme for performing an examination or an algorithm of actions [12]. Such clarity in the formulating of concepts allows you to clearly organize the process of forensic molecular genetic expert research, provide the necessary resources, and increase efficiency, including the clarity provided with the errors minimizing.

At the same time, the uncertainty of legal definitions of medical services, of the technology of genetic diagnostics as a technology mandatory in the treatment of the children with primary immune deficiency, leads to unclear organization and poor-quality provision of medical services as well as to the insufficient resource provision.

But in such countries as the Federal Republic of Germany [13], the Republic of Latvia [14], the issues of genetic diagnosis are regulated by a single omnibus act. In the United States, the issues of legal regulation of gene diagnostics shall be resolved at the level of the federal subjects, i.e. the states, which gives rise to a variety of approaches to the legal regulation of this issue. The object of special regulation in the United States is though the research in the field of gene therapy (genotherapy) aimed at correction of the genetic defects using genetic engineering methods [15].

Both, Germany and the United States, are federal states with a Romano-German legal system that is close to Russia, so their experience in regulating genetic diagnostics is interesting and acceptable for the Russian Federation.

\section{Results and Discussion}

Fatal outcomes can be avoided though, including violations of patients' rights resulted by non-timely providing of high-quality medical care, if such a simple and promising method for early detection of diseases is used, such as mass examination of pregnant women or prenatal screening of newborns, or neonatal screening [16], [17]. Further, after receiving the results of such examination, it is necessary to consult the parents of the child patients and prescribe treatment in a timely manner.

But the right of a child patient with SCID can be violated as a result of the fact that a complex of medical manipulations (or medical services), which include immunoglobulin replacement therapy, bone marrow transplantation, hematopoietic stem cells and gene therapy, will not be available to him.

One of the reasons for the unavailability is the fact that such medical services can only be provided by level
II and III medical institutions. As a rule, this type of medical institutions is located in big cities. In order to ensure access to such services, each region is developing a procedure for providing patients with PID-based diseases with high-tech medical care in specialized medical institutions (inpatient and day hospital settings). The presence in Federal Law No. 323-FZ of Article 34 on specialized, high-technological medical care, is surely a positive factor in this aspect.

In each region, the Procedure for providing medical care to patients with any diseases, including diseases associated with PID and SCID, has been being developed. The content of this document includes a description of the conditions, forms of care, the duration of treatment, the list of medical and diagnostic services, the content of drug therapy, criteria for the effectiveness of treatment, the name of medical institutions where they can provide the necessary type of care. Such a regulatory document, for example, exists in the Sverdlovsk region [18].

But to implement this regulatory document and the appropriate treatment for child patients we need immunology departments and permanent places for replacement therapy, which are only available in regional children's clinical hospitals. Unfortunately, the issues of financing hospitals that receive patients with diseases caused by PID and SCID are often not resolved: their treatment is expensive. Let us note that this problem is relevant for many countries [19], [2].

Organizational and financial difficulties in the provision of medical services for child patients are compounded, because in the Russian Federation and, accordingly, in the regions, there is no standard of primary healthcare for diseases caused by the human immune deficiency virus (HIV). Although there is such a standard for adults [20]. The disadvantage of the situation is that that the general provisions for the development of clinical recommendations or treatment protocols are established in the standard.

It is the standard that defines the scope and indicators that are used to assess the quality of medical services in the treatment of a specific disease, with a specific syndrome, or in a specific clinical situation. The value of this type of standard can be compared with the administrative standard for the organization and provision of public services. But, unfortunately, there is no such standard of primary healthcare for children with a disease caused by PID.

\section{Conclusion}

Thus, on the one hand, we can recognize that certain conditions for the provision of medical services for the children with SCID have been created in the Russian Federation. On the other hand, the absence of a federal law on mandatory genetic diagnostics creates organizational and financial difficulties.

The difficulties are compounded by the lack of a standard of primary healthcare for children with primary immune deficiency disease. As a result, there are problems that affect the observance of rights of the 
patients to timely receive a range of medical services, which are primarily essential for genetic diagnosis.

To solve the above problems, it is necessary to take both organizational and rule-making decisions. Firstly, it is necessary to develop a standard of primary health care for children with primary immunodeficiency disease, and, secondly, to increase funding for this area of public relations.

I would also like to note that, in our deep conviction, all the investments made should lead to the preservation and increase of human capital in such a difficult demographic situation for our country.

\section{Acknowledgments}

The study was carried out with the financial support of the Russian Federal Property Fund within the framework of scientific project No. 18-29-14059.

\section{References}

1. I. Tuzankina, S. Deryabina, M. Bolkov, Primary immune deficiency at an early age (Izhevsk, Print LLC, 2018)

2. M. Gallo, Agostiniani, R. Pintus, V. Fanos, The child with medical complexity, Italian Journal of Pediatrics, 47, 1 (2021)

3. D. Penela-Sánchez, S. Ricart, N. Vidiella, J.J. García-García, A study of paediatric patients with complex chronic conditions admitted to a paediatric department over a 12-month period, Anales de Pediatria, Sep 21 (2020)

4. N. Carrilero, A. Dalmau-Bueno, A. García-Altés, Comorbidity patterns and socioeconomic inequalities in children under 15 with medical complexity: A population-based study, BMC Pediatrics, 20(1), 30 (2020)

5. W. S. Looman, Y.-S. Park, T. T. Gallagher, E. V. Weinfurter, Outcomes research on children with medical complexity: A scoping review of gaps and opportunities, Child: Care, Health and Development, 46(1), 121-131 (2020)

6. E. Zaitseva, M. Bolkov, L. Voronina, To the issue of the socialization of the patients with PID, Russian Immunological Journal, 13(22), 1028-1030 (2019)

7. On the basics of public health protection in the Russian Federation: Federal Law No. 323-FZ dd. 21.11.2011. Retrieved from: http://www.consultant.ru [Accessed: 30.03.2021].

8. N. Mahlaoui, B. Gathmann, G. Kindle, et al., The European Society for Immune deficiencies (ESID) Registry: recent advancements in the epidemiology of Primary Immune deficiencies and how does that translate in clinical care, Rare diseases and orphan drugs, 1(4), 25-27 (2014)
9. S. Deryabina, I. Tuzankina, E. Vlasova, M. Bolkov, V. Shershnyov, Neonatal screening for Severe Combined Immune Deficiency in Russia: the beautiful far away or tomorrow's reality? Issues on modern paediatrics, 16(1), 59-66 (2017)

10. S. Grishin, Crimes committed by medical workers as a result of improper performance of their professional duties (based on the materials of the judicial practice of the European part of Russia 2015-2017), pp. 1-14 (2018)

11. GOST R 50646-2012. The National Standard of the Russian Federation "Public services. Terms and definitions". Date of introduction: 2014-01-01.

12. The use of individual systems based on DNA polymorphism of amplified fragments (PDAF) in forensic medical examination of identification of a person and determination of kinship: Methodical instructions, No. 98/253 (approved by the Ministry of Health of Russia on 01.19.1999).

13. On Genetic Testing (GenDG): German law. July 31 (2009). Retrieved from: https://www.gesetze-iminternet.de/gendg/ [Accessed: 21.03.2021].

14. On the study of the human genome: the Law of Latvia. July 3 (2002). Retrieved from: https://www.dvi.gov.lv/en/legal-acts/humangenome-research-law/ [Accessed: 25.03.2021].

15. A. Sahipgareeva, Law regulations of genome research in the United States of America, The Bulletin of the University named after Kutafin, 4, 146-151 (2019)

16. E. Zaharova, The Programmes of mass screening: technical, social and ethical issues, Medical genetics, 3, 21-23 (2006)

17. A. Baranov, V. Albitsky, A. Ivanova et al., The incidents trends and the state of health of the children population of the Russian Federation, The Russian pediatric journal, 6, 4-9 (2012)

18. On the order of medical care provision for the children and teenagers with allergic reactions and diseases associated with immune deficiency: the order of the Ministry of Health Care of the Sverdlovsk region dd.04.07.2012 No.750-p. Retrieved from: http:// minzdrav.midural.ru [Accessed: 30.03.2021].

19. S. Daidone, A. Street, How much should be paid for specialized treatment? Social science \& medicine, 84, 110-118 (2013)

20. On approval of the standard of primary healthcare for adults with a disease caused by the human immune deficiency virus (HIV) (examination for diagnosis and preparation for treatment): The Order of The Ministry of Health of the Russian Federation No. 796n of 20.11.2018. Retrieved from: http:// minzdrav.midural.ru [Accessed: 30.03.2021]. 